\title{
O Protagonismo do Brasil no Histórico Acordo Global de Proteção à Biodiversidade
}

\author{
Brazil's Leading Role in the Historical Global Agreement for the \\ Protection of Biodiversity
}

\author{
Russell Mittermeier ${ }^{1}$, Patrícia Carvalho Baião, ${ }^{2,3}$, Lina Barrera ${ }^{1}$, Theresa Buppert', \\ Jennifer McCullough ${ }^{1}$, Olivier Langrand ${ }^{1}$, Frank Wugt Larsen ${ }^{1}$ \& Fabio Rubio Scarano ${ }^{2,4, *}$
}

\author{
${ }^{1}$ Conservation International, 2011 Crystal Drive, Suite 500, 22202, Arlington, VA, Estados Unidos \\ ${ }^{2}$ Conservation International, Rua Buenos Aires 68, 26 andar, CEP 20070-022, Rio de Janeiro, RJ, Brasil \\ ${ }^{3}$ Programa de Pós-graduação em Biodiversidade, Universidade Federal do Amapá - UNIFAP, \\ CEP 68908-130, Macapá, AP, Brasil \\ ${ }^{4}$ Laboratório de Ecologia Vegetal, Departamento de Ecologia, Centro de Ciências da Saúde, Instituto de Biologia, \\ Universidade Federal do Rio de Janeiro - UFRJ, CP 68020, CEP 21941-970, Rio de Janeiro, RJ, Brasil
}

Sob a sombra do fracasso de Copenhagen e após duas semanas de difíceis negociações, poucos acreditavam que a décima Conferência das Partes (COP10) da Convenção da Diversidade Biológica (CDB) das Nações Unidas (veja histórico na Tabela 1) teria um final feliz. Entretanto, nas primeiras horas do dia 30 de outubro de 2010, na cidade japonesa de Nagoya, 193 países do mundo encontraram o tão esperado consenso. O Brasil foi um importante protagonista das negociações e, com freqüência, auxiliou na intermediação e busca de acordo entre as nações cujas posições eram mais extremas. O novo acordo significará um passo decisivo na redução da atual taxa de extinção de espécies e garantirá que países em desenvolvimento e seus povos tradicionais possam se beneficiar das riquezas geradas por seus ecossistemas terrestres e aquáticos. Nessa coluna, avaliamos os principais resultados da COP-10 e discutimos o papel do Brasil no sucesso das negociações.

\section{O Acordo}

\section{Áreas protegidas}

Uma das 20 metas acordadas no plano estratégico para o período 2011- 2020 foi a de aumento das áreas protegidas no âmbito global. Até 2020, 17\% da superfície continental do planeta e $10 \%$ da área oceânica deverão estar sob proteção formal. Considerando que o mundo conta hoje com 12,9\% da sua superfície continental e cerca de $0,7 \%$ da área oceânica

\footnotetext{
${ }^{\star}$ Send correspondence to: Fabio Rubio Scarano

Conservation International, Rua Buenos Aires 68, 26 andar,

CEP 20070-022, Rio de Janeiro, RJ, Brasil

E-mail: f.scarano@conservacao.org
}

total nessa categoria, a meta é particularmente ambiciosa no que diz respeito aos ambientes marinhos, e moderadamente ambiciosa para ambientes terrestres. Ao longo das duas semanas de negociações em Nagóia, a discussão dessa meta esteve polarizada, tendo de um lado países como a Colômbia, a Costa Rica e o Equador que defendiam 25/15 (\% continental e marinha, respectivamente), e de outro, países como a China que defendiam uma meta menos ambiciosa de apenas 10/6 (note que $10 \%$ seria menos que o planeta já tem e que a meta vigente era de $10 \%$ terrestre em 2010 e $10 \%$ para oceanos em 2012). A posição defendida pelo Brasil foi de 20/10 e o resultado acordado ao final, $17 / 10$, indicou a flexibilidade de todos e a habilidade dos negociadores brasileiros em trazer a decisão para bem perto da proposta inicial do país.

A Conservação Internacional organizou, no segundo dia da COP10 em Nagóia, um evento que discutiu resultados recém obtidos por seus cientistas que indicavam que seriam necessários pelo menos $25 \%$ de áreas protegidas continentais e $15 \%$ de áreas protegidas marinhas para proteger a biodiversidade e garantir a manutenção dos serviços ambientais. Os $25 \%$ da superfície continental, indicado pela análise da Conservação Internacional, é a soma de um mínimo de $17 \%$ de território global necessário para preencher as lacunas de áreas não protegidas classificadas como de alta prioridade, tais quais as KBA (Key Biodiversity Areas ou Áreas-Chave para a Biodiversidade), mais uma faixa adicional de 6 a $11 \%$ para garantir estocagem adequada de biomassa de carbono em ecossistemas naturais. Portanto, trata-se de uma estimativa bastante conservativa, já que não inclui outros aspectos ligados à biodiversidade ou a proteção de outros serviços ambientais como, por exemplo, a proteção de mananciais de água. Quanto à área 
marinha, o quinto Congresso Mundial de Parques (Durban. África do Sul, 2003) da UICN (União Internacional para a Conservação da Natureza) recomendara a meta de 20-30\% para adequadamente preservar a biodiversidade oceânica e assegurar ambientes marinhos produtivos e saudáveis (http:// cmsdata.iucn.org/downloads/recommendationen.pdf). A estimativa conservativa da Conservação Internacional de 15\% para 2020 decorre do julgamento que esse já seria um primeiro largo e significativo passo no sentido de alcançar a meta projetada pelo congresso de parques da UICN. Esses estudos estão sendo ampliados, contemplando a inclusão de serviços ambientais adicionais tais como segurança de qualidade e acesso a água e segurança alimentar. Dados preliminares indicam que para garantir efetivamente a manutenção dos serviços ambientais globais, talvez seja preciso proteger aproximadamente $35-50 \%$ da superfície do planeta. Consideramos, portanto, que o acordo 17/10 para 2020 é ainda abaixo do necessário, mas que já representa um passo significativo em direção ao ideal.

\section{Redução das taxas de extinção e de perda de habitats}

Duas metas do Plano Estratégico para 2011-2020 se relacionam a esses tópicos. A meta 5 lida com perda de habitats naturais, enquanto a meta 12 com extinção de espécies. A discussão acerca dessas metas também esteve polarizada na COP10, com alguns países propondo eliminar completamente a extinção de espécies até 2020 , e outros defendendo texto sem meta numérica, com indicação vaga de diminuição das taxas atuais dentro das capacidades nacionais. Com relação à extinção de espécies, o consenso foi de evitar a extinção de todas as espécies sabidamente ameaçadas até 2020 , posição essa defendida pelo governo brasileiro. Em relação à perda de habitats naturais, as partes concordaram com a meta de reduzir a pelo menos à metade até 2020 e aonde possível chegar à zero.

Baseado em estimativas recentes lançadas no relatório "A Economia dos Ecossistemas e da biodiversidade (TEEB, do Inglês, The Economics of Ecosystem and Biodiversity), a Conservação Internacional defendeu a meta de extinção zero até 2020 e uma meta ambiciosa para a redução da perda de habitats naturais. De acordo com o TEEB, as taxas atuais de extinção e de destruição de habitats implicam em grandes perdas financeiras anuais e que áreas protegidas proporcionam 100 vezes mais benefícios que custos à economia global. Assim, ainda que o acordo represente um grande passo, a redução da taxa de perda de habitats pela metade até 2020 ainda implicará prejuízo significativo para o mundo, especialmente para países em desenvolvimento.

Tabela 1. Breve cronologia da Convenção da Diversidade Biológica (CBD) das Nações Unidas.

\begin{tabular}{|c|c|c|}
\hline Ano & Evento & Principais fatos \\
\hline 1992 & Eco-92, Rio de Janeiro, Brasil & $\begin{array}{c}\text { São criadas três convenções, no âmbito da ONU, para conter e reverter } \\
\text { a crise ambiental: a CBD, a Convenção de Mudanças Climáticas } \\
\text { (UNFCCC) e a Convenção de Combate à Desertificação (UNCCD). }\end{array}$ \\
\hline 1993 & & $\begin{array}{l}\text { CBD entra em ação com três objetivos globais: 1) conservar a } \\
\text { diversidade biológica; 2) garantir o uso sustentável dos componentes } \\
\text { da biodiversidade; e 3) garantir a repartição justa e equitativa dos } \\
\text { benefícios que derivam dos recursos genéticos. }\end{array}$ \\
\hline 2002 & $\begin{array}{l}\text { COP-6, CBD, Johanesburgo, } \\
\text { África do Sul }\end{array}$ & $\begin{array}{l}\text { Lançamento do primeiro plano estratégico para reduzir a perda de } \\
\text { habitats e extinção de espécies. }\end{array}$ \\
\hline 2006 & COP-8, CBD, Curitiba, Brasil & $\begin{array}{l}\text { Demandou ao grupo de trabalho ad hoc sobre acesso e repartição de } \\
\text { benefícios (ABS) que completasse seu trabalho antes da COP- } 10 \text {. }\end{array}$ \\
\hline $\begin{array}{l}2010 \\
\text { (Maio) }\end{array}$ & $\begin{array}{l}\text { Subsidiary Body on Scientific Technical } \\
\text { and Technological Advice (SBSTTA), } \\
\text { CBD, Nairobi, Quênia }\end{array}$ & $\begin{array}{l}\text { Constatação pelas partes que o planeta fracassou } \\
\text { em alcançar as metas lançadas em } 2002 .\end{array}$ \\
\hline $\begin{array}{l}2010 \\
\text { (Outubro) }\end{array}$ & COP-10, CBD, Nagóia, Japão & $\begin{array}{l}\text { Lançamento de novo plano estratégico com } 20 \text { metas para o período } \\
\text { de 2011-2020; acordo em torno do acesso e repartição de benefícios } \\
\text { (ABS) associados à biodiversidade. }\end{array}$ \\
\hline 2012 & COP-11, local por definir, Índia & $\begin{array}{l}\text { Modalidades dos compromissos financeiros } \\
\text { para ABS serão discutidas. }\end{array}$ \\
\hline 2012 & Rio +20 , Rio de Janeiro, Brasil & $\begin{array}{l}\text { Re-encontro das três convenções criadas em 1992, } \\
\text { para avaliação de seu sucesso. }\end{array}$ \\
\hline
\end{tabular}




\section{Acesso e repartição de benefícios}

Acesso e repartição de benefícios (ABS, do inglês Access and Benefit Sharing) é relacionado ao terceiro objetivo da CBD (ver Tabela 1) e é um dos mais controvertidos aspectos da convenção desde seu mandato em 1998, tendo sido objeto de intensas negociações desde 2002. Sem dúvida, foi também o ponto que mais suscitou divergências entre os países durante a COP10. Essencialmente, o protocolo de ABS negociado em Nagóia trata de como ter acesso aos recursos genéticos da natureza e de como compartilhar os benefícios derivados do uso dessa biodiversidade, baseado em termos mutuamente acordados entre as partes. $\mathrm{O}$ protocolo toca em assuntos delicados como direitos sobre patentes, propriedade intelectual, direitos de comunidades indígenas e locais ao conhecimento tradicional associado a recursos genéticos, bem como acerca de que forma benefícios devem ser compartilhados quando produtos medicinais, cosméticos e outros bens são criados a partir da biodiversidade. No mercado atual, muitos desses produtos têm sua origem biológica no mundo em desenvolvimento, mas o benefício por vezes fica no mundo desenvolvido que, historicamente, é onde se encontram os laboratórios que desenvolvem os produtos comercializáveis.

O Brasil desde o início da COP10 condicionou a aprovação dos demais acordos ao acordo em ABS, no que foi seguido por vários outros países do mundo em desenvolvimento. Esse posicionamento foi essencial para impulsionar os demais países na direção de um acordo quanto ao ABS. Agora acordado, o "Protocolo de Nagóia sobre Acesso aos Recursos Genéticos e o Compartilhamento Justo e Equitativo dos Benefícios Derivados de Seu Uso" (http:// www.cbd.int/nagoya/outcomes/) marca uma conquista histórica da CBD em direção ao cumprimento do seu terceiro objetivo. Graças ao Japão ter submetido um texto, um dia antes do término da COP10, que constituía um bom compromisso entre países de norte e sul, consenso foi alcançado em tópicos que dividiam as partes signatárias há anos - incluindo o escopo do protocolo e a definição de utilização e derivados - em geral através do uso de linguagem aberta e da eliminação de trechos particularmente polêmicos. O protocolo também inclui considerações acerca de um mecanismo multilateral global de repartição de recursos que pode tratar de situações específicas onde ainda não haja consenso estabelecido. Embora essa abordagem possa criar algumas ambigüidades e questões acerca de sua efetiva implementação, o Protocolo de Nagóia emerge como um importante avanço.

\section{Financiamento}

Outro ponto de contenção para o governo brasileiro, no que também foi seguido por vários outros países em desenvolvimento, dizia respeito ao financiamento das várias ações previstas no plano estratégico para o período 2011-2020. Diante do fracasso no alcance das metas previstas para 2010, esses países condicionaram o acordo no novo plano estratégico a um compromisso de financiamento por parte de países do mundo desenvolvido, reconhecendo também a necessidade de investimentos nacionais por parte dos países em desenvolvimento. Novos compromissos financeiros, além do já anunciado pela Alemanha ao término da COP9 (sediado em Bonn, 2008), demoraram a aparecer, mas a três dias do fim das negociações, o Japão anunciou um compromisso de 2 bilhões de dólares, e foi seguido pela Grã-Bretanha, ainda que com uma menor soma bem inferior, e pela França, que se comprometeu com 200 milhões de dólares por ano ao longo dos próximos quatro anos e, a partir de 2014, 500 milhões de dólares por ano. Adicionalmente, os doadores reabasteceram o Global Environmental Facility (GEF), um fundo fiduciário multilateral estabelecido para financiar as convenções do clima e da biodiversidade, na ordem de 4,25 bilhões de dólares para o período de 2010-2014, que representa um aumento de $37 \%$ sobre os quatro anos anteriores.

A posição apresentada conjuntamente pela Conservação Internacional e pela Birdlife International era de investimentos na ordem de 0,3\% do PIB dos países do OECD (Organisation for Economic Co-operation and Development), que representa um montante de 125 bilhões de dólares. Ainda que os compromissos já anunciados estejam bastante aquém dessa proposta, esses foram bem recebidos e permitiram o acordo.

\section{Outros pontos importantes}

Merecem destaque ainda os seguintes aspectos:

- Ficou definida a criação, independente da CBD, do IPBES (Painel Intergovernamental de Biodiversidade e Serviços Ambientais), que seria o análogo ao IPCC (Painel Intergovernamental de Mudanças Climáticas), até Janeiro de 2011. O Brasil é um dos candidatos para sediar o Painel;

- Alinhamento com a convenção do clima: houve um reconhecimento da crescente interrelação entre conservação da biodiversidade, mudanças climáticas e desenvolvimento. Isso ficou evidente no enquadramento das metas para 2020 e também na série de decisões acerca das contribuições da natureza para adaptação e mitigação às mudanças climáticas, assim como na erradicação da pobreza.

\section{Brasil: Protagonismo versus Lacunas}

Conforme já mencionado, o Brasil teve um papel decisivo nas negociações em Nagóia, assim como já o fizera em Copenhagen na $15^{\text {a }}$ Conferência das Partes (COP15) da Convenção do Clima. O reconhecimento do sucesso da delegação brasileira na COP10 se deveu a diversos fatores tais como: boa estratégia de negociação, negociadores habilidosos e bem treinados; envolvimento e coordenação 
entre vários ministérios; a eloqüência e o compromisso da Ministra do Meio Ambiente, Izabella Teixeira; boa representação do setor empresarial brasileiro; boa e atuante representação de ONGs atuantes no país; assim como vários acadêmicos de destaque. Agora é o momento de passarmos do discurso para a ação e do papel para a prática. Se o Brasil não quiser ficar devendo para o planeta em termos de áreas protegidas, precisará pelo menos aumentar em $70 \%$ a atual cobertura de áreas protegidas no continente e aumentar 10 vezes a cobertura protegida marinha, conciliando isso com geração de energia, produção de alimentos e combustíveis e construção de infra-estrutura. Se por um lado a Amazônia brasileira está protegida em quase $50 \%$ (incluindo unidades de conservação e terras indígenas), biomas como o cerrado, pantanal, caatinga, mata atlântica e pampa estão bem abaixo dos $17 \%$ agora lançados como meta para o planeta. O quadro marinho então, com seus 1,5\% atuais, é particularmente sério, ainda mais em tempos de pré-sal.

O país precisará o quanto antes desenhar uma estratégia robusta para alcançar essas metas em 10 anos e prontamente pô-la em prática, incluindo criação e consolidação de áreas protegidas; criação de mecanismos de geração de renda a partir da biodiversidade e de arcabouço legal em nível nacional para pagamentos por serviços ambientais; revisão de listas de espécies ameaçadas de extinção e monitoramento e recuperação das mesmas; dentre vários outros pontos. Tudo isso irá requerer desembolso e financiamento em escala muito superior ao que se tem atualmente, mas também irá demandar ciência e pessoal qualificado. Se por um lado, a expansão da rede de pós-graduação em áreas ligadas à biodiversidade está em franca expansão, assim como o impacto internacional da ciência produzida nesses temas pelo país, por outro lado, a ciência e a tomada de decisão ainda se comunicam muito mal, como vem sendo discutido aqui na "Natureza \& Conservação" (e.g., Lewinsohn 2010, Metzger 2010, Scarano \& Martinelli 2010).

O balanço de vinte anos da ECO-92 se aproxima. O evento que está sendo chamado de Rio+20, em 2012, será hora do Brasil definitivamente despontar como líder ambiental global. Para isso será preciso mais que habilidade de negociação, atributo que o país já possui. Será preciso liderar pelo exemplo, pondo em prática em território nacional as idéias que tão habilmente os negociadores brasileiros têm usado para convencer outros países da importância e valor da biodiversidade.

\section{Agradecimentos}

À delegação brasileira em Nagóia pelo trabalho comprometido e dedicado sob a liderança da Ministra Izabella Teixeira e do Ministro Paulino Carvalho e, particularmente, ao grande conservacionista e habilidoso negociador Secretário Braulio Dias. Somos gratos também à delegação da Conservação Internacional pelo apoio e trabalho em equipe.

\section{Referências}

Lewinsohn TM, 2010. A ABECO e o Código Florestal Brasileiro. Natureza \& Conservação, 8:100-101.

Metzger JP, 2010. O Código Florestal tem base científica? Natureza \& Conservação, 8:92-99.

Scarano FR \& Martinelli G, 2010. Brazilian list of threatened plant species: reconciling scientific uncertainty and political decision-making. Natureza \& Conservação, 8:13-18.

Recebido: Novembro 2010

Primeira Decisão: Novembro 2010

Aceito: Novembro 2010 